\title{
Flow boiling of ammonia in vertical small diameter tubes: Two phase frictional pressure drop results and assessment of prediction methods
}

\author{
M.H. Maqbool, B. Palm*, R. Khodabandeh \\ Royal Institute of Technology, KTH, Dept. Energy Technology, Division of Applied Thermodynamics and Refrigeration, Brinellvägen 68, 10044 Stockholm, Sweden
}

\section{A R T I C L E I N F O}

\section{Article history:}

Received 24 February 2011

Received in revised form

22 November 2011

Accepted 24 November 2011

Available online $\mathrm{xxx}$

\section{Keywords:}

Two phase

Pressure drop

Ammonia

Experimental study

\begin{abstract}
A B S T R A C T
Two phase pressure drops were measured for ammonia at a wide range of test conditions in two sizes of vertical mini channels. The test sections were made of stainless steel (AISI 316) tubes with internal diameter of $1.70 \mathrm{~mm}$ and $1.224 \mathrm{~mm}$ and a uniformly heated length of $245 \mathrm{~mm}$. Experiments were conducted at three saturation temperatures of $23^{\circ} \mathrm{C}, 33^{\circ} \mathrm{C}$ and $43^{\circ} \mathrm{C}$, the heat flux ranging from 15 to $355 \mathrm{~kW} / \mathrm{m}^{2}$ and the mass flux ranging from 100 to $500 \mathrm{~kg} / \mathrm{m}^{2} \mathrm{~s}$. The effect of the heat flux, the mass flux, the vapour quality, the saturation temperature and the internal diameter on the two phase pressure drop are presented in this article. Some generalized two phase pressure drop correlations suggested for macro and micro scale channels are examined by comparing them with our experimental data. None of the examined correlations agreed well with the test data. A new correlation (modified form of Tran et al. correlation) is proposed which is able to predict the experimental data with MAD of $16 \%$ and $86 \%$ of the data is within $\pm 30 \%$ range.
\end{abstract}

(c) 2011 Elsevier Masson SAS. All rights reserved.

\section{Introduction}

The transport phenomena in micro channels have gained importance because micro geometries offer higher cooling capability for micro technologies [1]. The advancement in micro fabrication is also important for the application of mini and micro channels. It enables us to precisely manufacture the flow channels ranging from a few micrometres to several hundred micrometres or more [2]. Mini channels offer higher heat transfer capabilities and higher heat transfer coefficients than macro channels [3]. Mini channels can be used for different applications such as electronic cooling, biomedical engineering, automotive industry and compact refrigeration systems etc. Despite many advantages of using mini channels like reduced size, low fluid inventory, reduced cost due to minimum material requirement and compactness, the disadvantage may be higher pressure drop if the system is not designed properly. To get higher heat transfer without increasing pressure drop is a major research task for micro geometries.

Only few published studies are available for mini and micro channels regarding two phase pressure drop of ammonia, and some of the related studies are mentioned below:

\footnotetext{
* Corresponding author. Tel.: +460 0790 7453; fax: +46 08204161 .

E-mail addresses: maqbool@kth.se (M.H. Maqbool), bpalm@energy.kth.se (B. Palm), rahmat@energy.kth.se (R. Khodabandeh).
}

Ungar and Cornwell [4] performed flow boiling experiments to investigate two phase pressure drop of ammonia in mini and micro channels. A range of horizontal test sections of diameter $1.46,1.78$, 2.58 and $3.15 \mathrm{~mm}$ respectively were used. The two phase frictional pressure drop data was compared with several macro scale correlations. Apart from the homogeneous model with the viscosity definition of McAdams et al. [5], none of the macro scale correlations predicted the data well.

Two phase adiabatic pressure drop in a micro channel of $148 \mu \mathrm{m}$ diameter was investigated by Brandon and Hrnjak [6]. A number of refrigerants like ammonia, propane, R410a and R134a were tested in this study. The measured data was compared with several correlations but only Mishima and Hibiki [7] correlation was in good agreement with the experimental data of Ammonia. The authors proposed a new correlation based on Chisholm interaction parameter. The new correlation predicted the data of all refrigerants with a Mean Absolute Deviation (MAD) of $12.6 \%$.

Kabelac and Buhr [8] performed flow boiling experiments with ammonia in smooth and low finned horizontal test sections of $10 \mathrm{~mm}$ internal diameter and a length of $450 \mathrm{~mm}$. The test conditions were; mass flux range $50-150 \mathrm{~kg} / \mathrm{m}^{2} \mathrm{~s}$, vapour quality range $0-0.9$, saturation temperatures -40 to $4{ }^{\circ} \mathrm{C}$ and a heat flux range of $17-75 \mathrm{~kW} / \mathrm{m}^{2}$. It was observed that at the same test conditions, the pressure drop of the finned test section was about $50 \%$ higher than for the smooth tubes. They compared their experimental data of smooth and finned tubes with many correlations. Among all the 
prediction methods used, the Chisholm [9] correlation was found to be in best agreement with their experimental data.

Da Silva Lima et al. [10] performed experiments to investigate flow patterns and two phase pressure drop of ammonia in a $14 \mathrm{~mm}$ diameter stainless steel tube. The expected trends were observed, i.e. that the two phase pressure drop increases with increasing mass flux and vapour quality. They also compared two phase frictional pressure drop in diabatic and adiabatic flows and found no noticeable influence on frictional pressure drop. Low accuracy of predicting methods were observed except for the correlation of Grönnerud [11] with $93 \%$ of the data within an error band of $30 \%$, and the model of Quibén and Thome [12] which best predicted the data with $89 \%$ of all data within $20 \%$ error band.

One of the objectives of this study is to add data of ammonia for mini and micro channels because of the lack of published data in the literature. This data is particularly interesting because of the very different thermo physical properties of ammonia compared to other refrigerants commonly tested in mini channels. To include the ammonia data will therefore be valuable in the effort to formulate generalised correlations for the prediction of two phase frictional pressure drop in mini and micro channels. Another reason for understanding the behaviour of two phase flow of the natural working fluid ammonia is due to increased concerns of ozone depletion and global warming, as increased knowledge of the performance of this refrigerant may contribute to its use as a substitute to HCFC and HFC refrigerants.

\section{Experimental set up and test procedure}

A schematic of the experimental set up is shown in Fig. 1. A magnetic gear pump (ISMATEC, type MCP-Z standard) circulated the refrigerant, and a (MicroMotion DS006) Corioli mass flow meter was used to measure the flow rate. A pre heater adjusted the inlet temperature of the fluid before the test section. A filter of $7 \mu \mathrm{m}$ was used to restrict any particles from entering the test section.

The test sections consisted of metal (AISI 316 stainless steel) tubes with inner diameters of $1.70 \mathrm{~mm}$ and $1.224 \mathrm{~mm}$. The roughness of the test sections were determined by scanning the inner surface using a method called conical stylus profilometry and scanned images of inner surface of both test sections can be seen in Figs. 2 and 3. Five profiles of the inner surface of each test section were obtained. It was observed that the inner surface of the $1.70 \mathrm{~mm}$ tube is smoother than that of the $1.224 \mathrm{~mm}$ diameter tube. The details of the roughness test results are shown in Table 4 where $R_{a}$ represents the arithmetic mean roughness, $R_{v}$ the maximum valley depth and $R_{p}$ is the maximum peak height. Direct electric heating was applied to the test section using a high current, low voltage DC power supply. This direct heating ensured homogeneous heat flux over the test section. The test loop was insulated by thermal insulation. The wall temperatures of the test section were measured by T-type thermocouples. The tip of each thermocouple was electrically insulated and then attached at the outer wall with special epoxy which was thermally conductive and electrically insulating. To measure the fluid temperature at different points in the test loop, T-type thermocouples were installed at the suction and discharge of the pump, at the condenser outlet and at the inlet and outlet of the test section.

The system pressure was monitored by an absolute pressure transducer (Druck PDCR 4060, 20 bar) and the pressure drop by differential pressure transducers (Druck PDCR 2160, 350 and 700 mbar). The heat flux was calculated from the current and voltage of the power input and the surface area of the test section. The inner
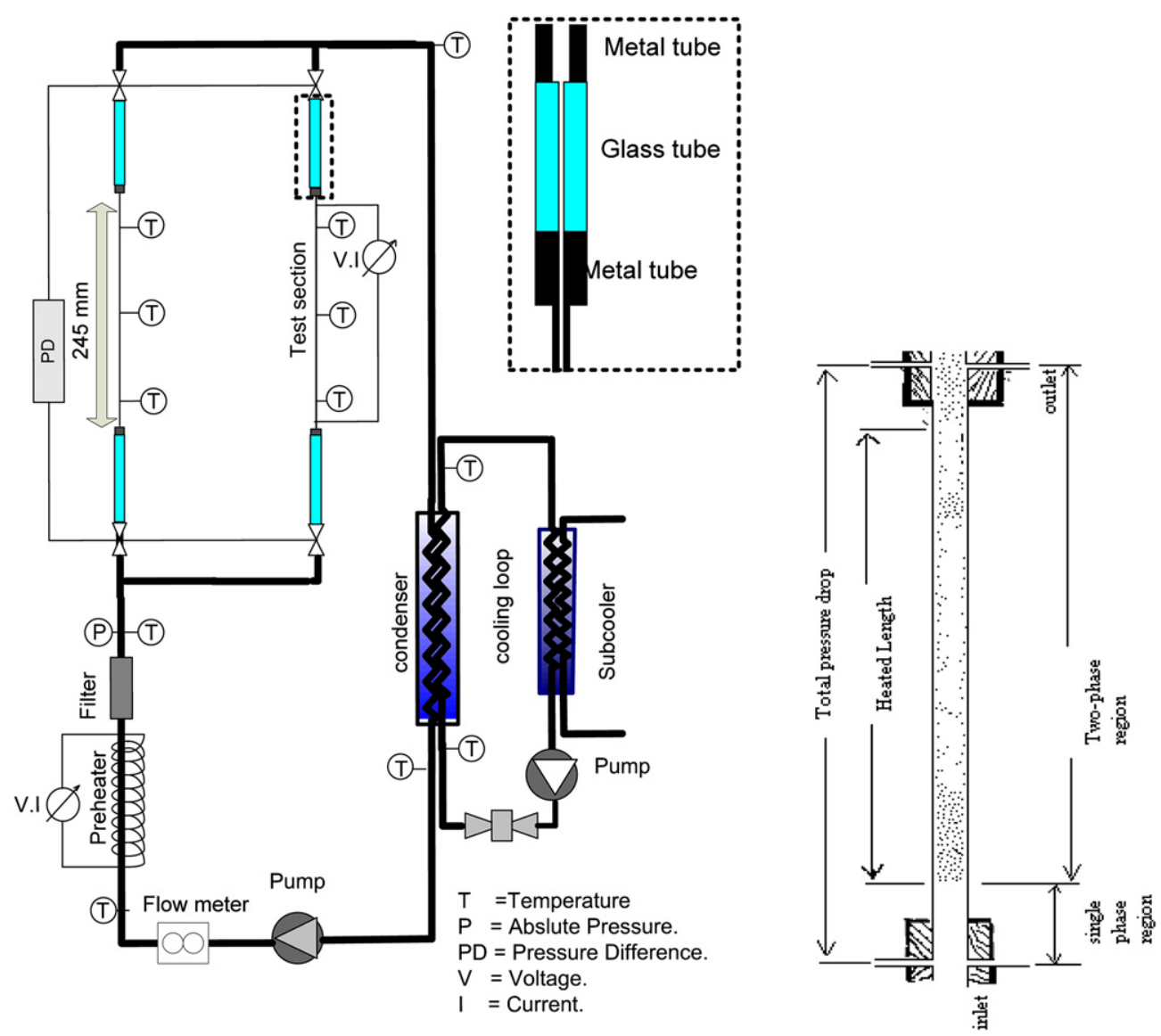

Fig. 1. Schematic diagram of experimental test rig. 


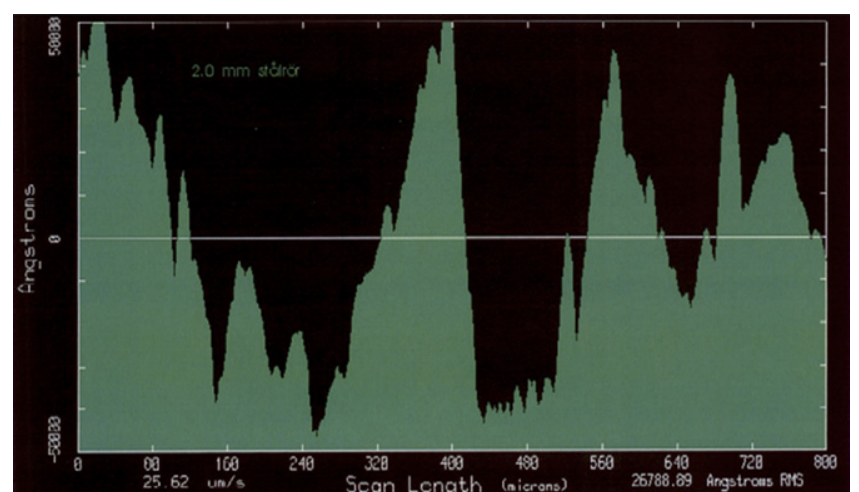

Fig. 2. Characterisation of inner surface roughness of $1.224 \mathrm{~mm}$ tube.

wall temperatures were calculated by correcting the measured outer wall temperatures using the heat conduction equation. After absorbing heat from the test section, the refrigerant entered the condenser and was condensed to liquid, then it was cooled in the sub-cooler. Finally the refrigerant entered the pump and the loop was completed. The uncertainty analysis of the operating parameters is tabulated in Table 1.

Heat losses to ambient were experimentally estimated by the following method: Without any fluid flow, the wall temperatures were set at the desired level by adjusting the electric heating. The data was recorded at different heat fluxes and the temperature difference between wall and ambient was plotted versus the applied heat flux. On the basis of the equation of the plot, heat loss calculations were done. For low heat fluxes, the heat loss was $1-2 \%$ of the applied power and for high heat fluxes, it was less than $1 \%$.

All tests were performed under steady state conditions. After achieving steady state conditions, the data was recorded for almost $5 \mathrm{~min}$. The temperatures, the mass flow and the system pressure were recorded using a data logger connected to a computer. The data was displayed using HP VEE software. All the thermal and transport properties including enthalpy, density, viscosity and thermal conductivity of ammonia were calculated using REFPROP 7 developed by NIST (National Institute of Standards and Technology).

\section{Data reduction}

The thermodynamic vapour quality at any vertical location $(z)$ was calculated as;

$x(z)=\frac{q^{\prime \prime} \cdot \pi D \cdot\left(z-z^{\circ}\right)}{A_{c} \cdot G \cdot i_{l v}}$

where $q^{\prime \prime}$ is the heat flux which is the ratio of the power applied to

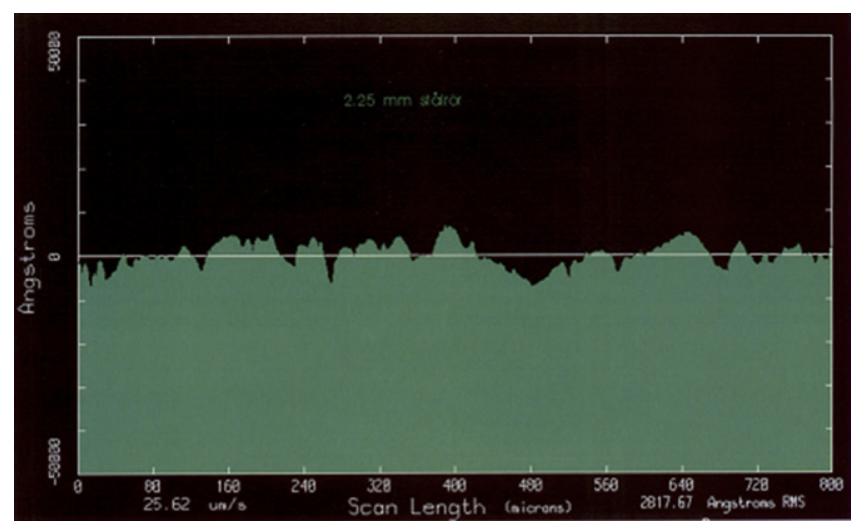

Fig. 3. Characterisation of inner surface roughness of $1.70 \mathrm{~mm}$ tube. the test section and the internal surface area based on the heated length, $A_{c}$ the cross-sectional area and $z^{\circ}$ is the location on the heated section at which saturated conditions would be reached, calculated as;

$z^{\circ}=\frac{m_{\mathrm{NH}_{3}} \cdot C_{p} \cdot\left(T_{\mathrm{sat}}-T_{\mathrm{in}}\right)}{q^{\prime \prime} \cdot \pi D}$

$C_{p}$ is the specific heat of the fluid, $\dot{m}$ the mass flow rate of ammonia, $T_{\text {sat }}$ is the saturation temperature and $T_{\text {in }}$ the inlet temperature of the test section.

The single phase friction factor for fully developed laminar flow was calculated as follows;

If $R e<2000$ then $f_{\text {lam }}=64 / R e$

For single phase turbulent flow the Blasius [13] correlation was used:

If $R e>2000$ then $f_{\text {turb }}=0.316 / R e^{0.25}$

The measured pressure drop is the sum of inlet contraction, outlet expansion, two phase flow and inlet single phase flow pressure drops.

$(\Delta P)_{\text {measured }}=(\Delta P)_{\mathrm{ic}}+(\Delta P)_{\mathrm{oe}}+(\Delta P)_{\mathrm{tp}}+(\Delta P)_{\mathrm{sp}}$

In the cases tested, the two phase pressure drop varied from 75 to $92 \%$ of the total measured pressure drop. The proportion of single phase pressure drop varied from 3 to $21 \%$. The proportion of inlet compression and outlet expansion both vary from 1 to $5 \%$.

$(\Delta P)_{\text {ic }}$ represents pressure drop due to the contraction at the inlet and can be calculated as [14];

$(\Delta P)_{\text {ic }}=\xi_{\text {ic }} \frac{\rho\left(u_{2}^{2}-u_{1}^{2}\right)}{2}$

where $\xi_{\text {ic }}=f\left(\frac{\operatorname{lam}}{\text { turb }}, \frac{A_{2}}{A_{1}}\right)$ is the drag compression factor

$(\Delta P)_{\text {oe }}$ represents pressured drop due to outlet expansion which can be calculated as [14];

$(\Delta P)_{\text {oe }}=\frac{G^{2} \sigma(1-\sigma)}{\rho_{L}}\left[\frac{x_{\text {exit }}^{2}}{\alpha_{\text {exit }}}\left(\frac{\rho_{L}}{\rho_{g}}\right)+\frac{\left(1-x_{\text {exit }}\right)^{2}}{\left(1-\alpha_{\text {exit }}\right)}\right]$

where $\sigma=A_{1} / A_{2}$

$(\Delta P)_{\text {sp }}$ represents the single phase pressure drop at the inlet of test section.

$(\Delta P)_{\mathrm{sp}}=\left|(\Delta P)_{\mathrm{sp}}\right|_{\mathrm{fric}}+\left|(\Delta P)_{\mathrm{sp}}\right|_{\text {grav }}$

where $\left|(\Delta P)_{\text {sp }}\right|_{\text {grav }}=g L_{\text {sp }} \rho_{L}$

and $\left|(\Delta P)_{\text {sp }}\right|_{\text {fric }}=f \frac{\rho_{l} u^{2}}{2} \frac{L_{\mathrm{sp}}}{D_{i}}$

where, if $R e<2000$ then $f_{\text {lam }}=64 / R e$

and if $R e>2000$ then $f_{\text {turb }}=0.316 / R e^{0.25}$

Table 1

Uncertainty of operating parameters

\begin{tabular}{lll}
\hline Parameter & Operating range & Uncertainty \\
\hline $\mathrm{D}(\mathrm{mm})$ & $1.70,1.224$ & $\pm 0.007, \pm 0.009$ \\
$\mathrm{G}\left(\mathrm{kg} / \mathrm{m}^{2} \mathrm{~s}\right)$ & $100-500$ & $\pm 3-3.5 \%$ \\
$\mathrm{q}^{\prime \prime}\left(\mathrm{kW} / \mathrm{m}^{2}\right)$ & $15-355$ & $\pm 1.25-3 \%$ \\
$\mathrm{dP}(\mathrm{mbar})$ & $0-700$ & \pm 1 \\
$\mathrm{~T}_{\text {sat }}\left({ }^{\circ} \mathrm{C}\right)$ & $23,33,43$ & \pm 0.1 \\
$\mathrm{x}_{\text {th }}(-)$ & $0-1.1$ & $\pm 3-4 \%$ \\
\hline
\end{tabular}


Table 2

Pressure drop correlations of macro scale.

\section{Correlation \\ Homogeneous model}

Friedel [22]

Lockhart-Martinelli [20]

Müller Steinhagen and Heck [23]

Grönnerud [11]

Chisholm [9]
Equation

$\left(\frac{\mathrm{d} p}{\mathrm{~d} z}\right)_{f}=\frac{2 f_{\mathrm{tp}} G^{2}}{D \rho_{t p}}, \rho_{\mathrm{tp}}=\left(\frac{x}{\rho_{V}}+\frac{(1-x)}{\rho_{L}}\right)^{-1}, f_{\mathrm{tp}}=\frac{16}{R e_{\mathrm{tp}}}$ for $\operatorname{Re}<2000, f_{\mathrm{tp}}=0.079 \operatorname{Re}^{-0.25}$ for $\operatorname{Re}>2000, \operatorname{Re} e_{\mathrm{tp}}=\frac{\mathrm{GD}}{\mu_{\mathrm{tp}}}$

Three forms of viscosity models are; McAdams et al. [5] $\mu_{\mathrm{tp}}=\left(\frac{x}{\mu_{V}}+\frac{(1-x)}{\mu_{L}}\right)^{-1}$

Chicchitti et al. [19] $\mu_{\text {tp }}=\left(x \mu_{V}+(1-x) \mu_{L}\right)$

Dukler et al. [28] $\mu_{\mathrm{tp}}=\rho_{\mathrm{tp}}\left(\frac{x \mu_{v}}{\rho_{V}}+\frac{(1-x) \mu_{L}}{\rho_{L}}\right)$

$\left(\frac{\mathrm{d} p}{\mathrm{~d} z}\right)_{f}=\left(\frac{\mathrm{d} p}{\mathrm{~d} z}\right)_{\mathrm{Lo}} \Phi_{\mathrm{LO}}^{2}, \Phi_{\mathrm{LO}}^{2}=E+\frac{3.24 \mathrm{FH}}{\mathrm{Fr}^{0.045} W e^{0.035}}$

$F r=\frac{G^{2}}{g D \rho^{2} H}, F=x^{0.78}(1-x)^{0.225}, H=\left(\frac{\rho_{L}}{\rho_{V}}\right)^{0.91}\left(\frac{\mu_{V}}{\mu_{L}}\right)^{0.19}\left(1-\frac{\mu_{V}}{\mu_{L}}\right)^{0.7}$

$W e=\frac{G^{2} D}{\sigma \rho H}$ with $\rho_{H}=\left(\frac{x}{\rho_{V}}+\frac{(1-x)}{\rho_{L}}\right)^{-1}, E=(1-x)^{2}+x^{2} \frac{\rho_{L} f_{\mathrm{VO}}}{\rho_{V} f_{\mathrm{LO}}}$

$f_{\mathrm{LO}}=\frac{16}{R e_{\mathrm{LO}}}$ for $R e_{\mathrm{LO}}<2000, f_{\mathrm{LO}}=0.079 R e_{\mathrm{LO}}^{-0.25}$ for $R e_{\mathrm{LO}}>2000$

$f_{\mathrm{VO}}=\frac{16}{R e_{\mathrm{VO}}}$ for $R e_{\mathrm{VO}}<2000, f_{\mathrm{VO}}=0.079 R e_{\mathrm{VO}}^{-0.25}$ for $R e_{\mathrm{VO}}>2000$

$R e_{\mathrm{LO}}=\frac{\mathrm{GD}}{\mu_{L}}, R e_{\mathrm{VO}}=\frac{\mathrm{GD}}{\mu_{V}},\left(\frac{\mathrm{d} p}{\mathrm{~d} z}\right)_{\mathrm{Lo}}=f_{\mathrm{LO}} \frac{2 G^{2}}{D \rho_{L}}$

$\left(\frac{\mathrm{d} p}{\mathrm{~d} z}\right)_{f}=\left(\frac{\mathrm{d} p}{\mathrm{~d} z}\right)_{L} \Phi_{L}^{2}, \Phi_{L}^{2}=1+\frac{C}{X}+\frac{1}{X^{2}}$ with $C$ given by:

$C_{\mathrm{tt}}=20, C_{\mathrm{vt}}=12, V_{\mathrm{tv}}=10, C_{\mathrm{vv}}=5$

\begin{tabular}{c|c|c}
\hline Liquid & Gas & C-value \\
\hline Laminar & Laminar & 5 \\
Laminar & Turbulent & 12 \\
Turbulent & Laminar & 10 \\
Turbulent & Turbulent & 20 \\
\hline
\end{tabular}

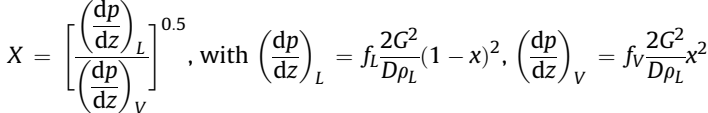

$f_{L}=\frac{16}{R e_{L}}$ for $\operatorname{Re}_{\mathrm{L}}<2000, f_{L}=0.079 R e_{L}^{-0.25}$ for $\operatorname{Re}_{\mathrm{L}}>2000$

$f_{V}=\frac{16}{R e_{V}}$ for $R e_{V}<2000, f_{V}=0.079 R e_{V}^{-0.25}$ for $R e_{V}>2000$

$R e_{L}=\frac{\mathrm{GD}}{\mu_{L}}(1-x), R e_{\mathrm{VO}}=\frac{\mathrm{GD}}{\mu_{V}} x$

$\left(\frac{\mathrm{d} p}{\mathrm{~d} z}\right)_{f}=F(1-x)^{1 / 3}+\left(\frac{\mathrm{d} p}{\mathrm{~d} z}\right)_{V O} x^{3}$

With $F=\left(\frac{\mathrm{d} p}{\mathrm{~d} z}\right)_{\text {LO }}+2\left[\left(\frac{\mathrm{d} p}{\mathrm{~d} z}\right)_{\text {VO }}-\left(\frac{\mathrm{d} p}{\mathrm{~d} z}\right)_{\mathrm{LO}}\right] x$

$\left(\frac{\mathrm{d} p}{\mathrm{~d} z}\right)_{f}=\left(\frac{\mathrm{d} p}{\mathrm{~d} z}\right)_{L} \Phi_{L}^{2},\left(\frac{\mathrm{d} p}{\mathrm{~d} z}\right)_{L}=f_{\mathrm{Lo}} \frac{2 G^{2}}{D \rho_{L}}(1-x)^{2}$

$\Phi_{L}^{2}=1+\left(\frac{\mathrm{d} p}{\mathrm{~d} z}\right)_{F r}\left[\frac{\frac{\rho_{L}}{\rho_{V}}}{\left(\frac{\mu_{L}}{\mu_{V}}\right)^{0.25}}-1\right],\left(\frac{\mathrm{d} p}{\mathrm{~d} z}\right)_{F r}=f_{F r}\left[x+4\left(x^{1.8}-x^{10} f_{F r}^{0.5}\right)\right]$

$F r_{L}=\frac{G^{2}}{g D \rho_{L}^{2} H}$, If $F r_{L}>1$ then $f_{F r}=1$

If $F r_{L}<1$ then $f_{F r}=F r_{L}^{0.3}+0.0055\left(\operatorname{In} \frac{1}{F r_{1}}\right)^{2}$

$\left(\frac{\mathrm{d} p}{\mathrm{~d} z}\right)_{f}=\left(\frac{\mathrm{d} p}{\mathrm{~d} z}\right)_{\mathrm{Lo}} \Phi_{\mathrm{LO}}^{2}, \Phi_{\mathrm{LO}}^{2}=1+\left(Y^{2}-1\right) \cdot\left[\mathrm{Bx}^{0.875}(1-x)^{0.875}+x^{1.75}\right]$

$Y^{2}=\frac{\left(\frac{\mathrm{d} p}{\mathrm{~d} z}\right)_{\mathrm{VO}}}{\left(\frac{\mathrm{d} p}{\mathrm{~d} z}\right)_{\mathrm{LO}}} \Phi_{\mathrm{LO}}^{2}$ and $\left(\frac{\mathrm{d} p}{\mathrm{~d} z}\right)_{\mathrm{VO}}=f_{\mathrm{Vo}} \frac{2 G^{2}}{D \rho_{V}}$

If $0<Y<9.5 B=\frac{55}{G^{2}}$ for $G \geq 1900 \frac{\mathrm{kg}}{\mathrm{m}^{2} \mathrm{~s}}, B=\frac{2400}{G}$ for $500<G<1900 \frac{\mathrm{kg}}{\mathrm{m}^{2} \mathrm{~s}}$

$B=4.8$ for $500<G$

If $9.5<Y<28, B=\frac{520}{Y^{0.5}}$ for $G \leq 600 \frac{\mathrm{kg}}{\mathrm{m}^{2} \mathrm{~s}}, B=\frac{21}{Y}$ for $G>600 \frac{\mathrm{kg}}{\mathrm{m}^{2} \mathrm{~s}}$

For $Y>28, B=\frac{15000}{Y^{2} G^{0.5}}$ 
Table 3

Pressure drop correlations of micro scale.

\begin{tabular}{ll}
\hline Correlation & Equation \\
\hline Mishima and Hibiki [7] & $\begin{array}{l}C=21\left(1-e^{-319 D}\right) \\
\text { This } C \text { value should be used with } \\
\text { Lockhart-Martinelli [20] Correlation. }\end{array}$ \\
Zhang and Webb [25] & $\left(\frac{\mathrm{d} p}{\mathrm{~d} z}\right)_{f}=\left(\frac{\mathrm{d} p}{\mathrm{~d} z}\right)_{\mathrm{Lo}} \Phi_{\mathrm{LO}}^{2}$ \\
& $\Phi_{\mathrm{LO}}^{2}=(1-x)^{2}+2.87 x^{2}\left(\frac{P}{P_{\mathrm{Crit}}}\right)^{-1}$ \\
Tran et al. [26] & $\left(\frac{\mathrm{d} p}{\mathrm{~d} z}\right)_{f}=\left(\frac{\mathrm{d} p}{\mathrm{~d} z}\right)_{\mathrm{Lo}} \Phi_{\mathrm{LO}}^{2}$, \\
& $\Phi_{\mathrm{LO}}^{2}=1+\left(4.3 Y^{2}-1\right) \cdot\left[\operatorname{Cox}^{0.875}(1-x)^{0.875}+x^{1.75}\right]$ \\
& Co $=\sqrt{\left.\frac{\sigma}{P_{\mathrm{crit}}}\right)^{-1.64}}$ \\
&
\end{tabular}

$(\Delta P)_{\text {tp }}$ represents the pressure drop due to two phase flow and it includes frictional, gravitational and acceleration part;

$(\Delta P)_{\mathrm{tp}}=(\Delta P)_{\mathrm{fric}}+(\Delta P)_{\mathrm{grav}}+(\Delta P)_{\mathrm{acc}}$

The two phase gravitational pressure drop is calculated as

$\left|(\Delta P)_{\mathrm{tp}}\right|_{\text {grav }}=g \sum_{i=1}^{i=n} L_{i}\left[\alpha \rho_{g}+(1-\alpha) \rho_{i}\right]_{i}$

And the acceleration pressure drop as

$\left|(\Delta P)_{\mathrm{tp}}\right|_{\text {acc }}=\frac{G^{2}}{\rho_{L}}\left[\frac{x_{\text {exit }}^{2}}{\alpha_{\text {exit }}}\left(\frac{\rho_{L}}{\rho_{g}}\right)+\frac{\left(1-x_{\text {exit }}\right)^{2}}{\left(1-\alpha_{\text {exit }}\right)}-1\right]$

where $\alpha$ is defined from Woldesemayat and Ghajar correlation [15];

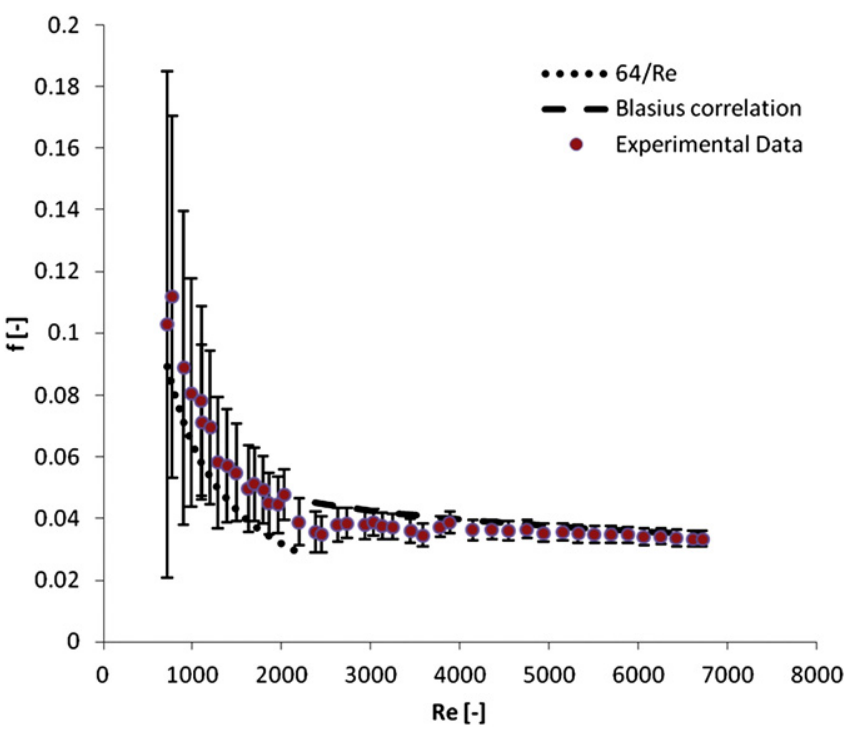

Fig. 4. Single phase friction factor versus Reynolds number for $1.224 \mathrm{~mm}$ tube.

In the homogeneous model, the liquid and gas phases are assumed to have the same velocity. In this model, only one phase, with average properties, is considered. Different definitions of average viscosity are reported in Table 2 . The separated flow model is based on the assumption that the two phases are segregated into separated flows that may have different velocities.

The macro scale correlations used in this study are tabulated in Table 2 .

\subsection{Micro scale correlations}

The two phase flow regimes in small diameters tubes are

$$
\alpha=\frac{U_{\mathrm{Sg}}}{U_{\mathrm{Sg}}\left(1+\left(\frac{U_{\mathrm{Sl}}}{U_{\mathrm{Sg}}}\right)\left(\frac{\rho g}{\rho L}\right)^{0.1}\right)+2.9\left[\frac{g D \sigma(1+\cos \theta)\left(\rho_{L}-\rho_{g}\right)}{\rho L^{2}}\right]^{0.25}(1.22+1.22 \sin \theta)^{\frac{P_{\text {patm }}}{P_{\text {system }}}}}
$$

The calculations have also been done using the homogeneous model but the Woldesemayat and Ghajar correlation [15] gave more coherent results.The frictional two phase pressure drop was estimated by subtracting the calculated gravitational and acceleration pressure drops mentioned above from the total two phase pressure drop. The calculated two phase gravitational and acceleration pressure drops vary from 15 to $30 \%$ of the two phase pressure drop.

\section{Two phase frictional pressure drop correlations}

\subsection{Macro scale correlations}

The two phase frictional pressure drop can be determined by different models. Generally, these can be divided into homogeneous and separated flow models.

Table 4

Roughness details of test sections.

\begin{tabular}{llll}
\hline Tube inner dimension & $R_{a}(\mu \mathrm{m})$ & $R_{v}(\mu \mathrm{m})$ & $R_{p}(\mu \mathrm{m})$ \\
\hline $1.70 \mathrm{~mm}$ & 0.21 & -0.73 & 0.80 \\
$1.224 \mathrm{~mm}$ & 2.55 & -5.08 & 9.58 \\
\hline
\end{tabular}

different from those in macro channels [3]. The flow in small diameter tubes is more influenced by surface tension than gravity effects, which is different from macro channels. Based on these differences, it may be assumed that the predicting methods for macro scale pressure drop may not work well for prediction of two phase pressure drop in micro tubes. Mostly micro scale correlations are modified forms of macro scale correlations and are developed by incorporating dominant effects of micro flow in macro scale correlations. Micro scale correlations used in this study are tabulated in Table 3.

\section{Experimental results and discussion}

To validate the instrumentation and the measurements in the test rig, single phase experiments were made. The results in terms of single phase friction factor plotted versus Reynolds number for the $1.224 \mathrm{~mm}$ tube are shown in Fig. 4. As can be seen in this figure, the experimental results correspond well to the classical correlations. The large error bars in the laminar region is due to the very low pressure drop in these cases. The accuracy of the pressure transducer is in this case limiting the accuracy. 


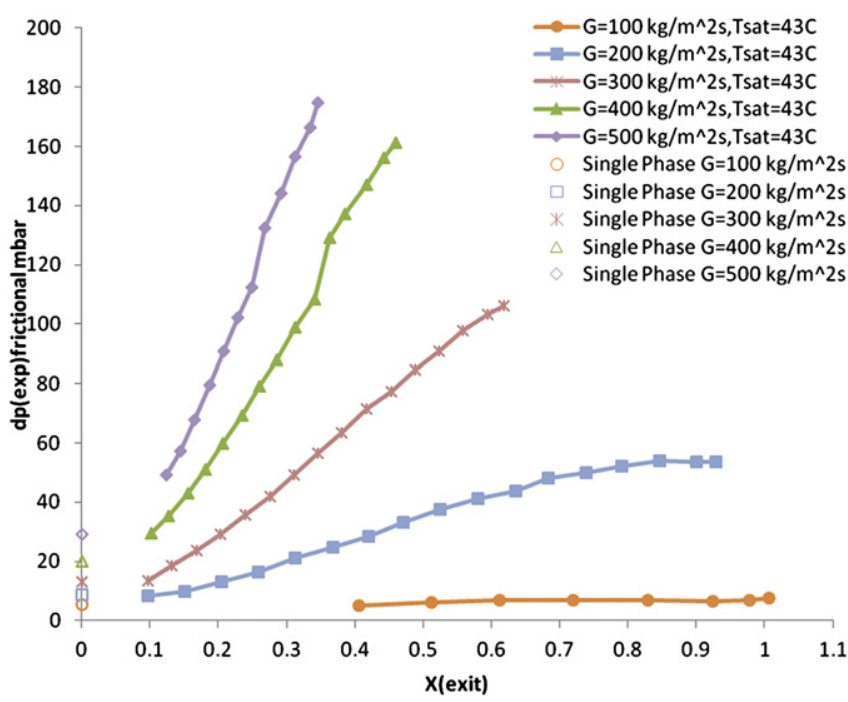

Fig. 5. Two phase frictional pressure drop versus exit vapour quality of $1.70 \mathrm{~mm}$ tube at $T_{\text {sat }}=43^{\circ} \mathrm{C}$.

\subsection{Effect of mass flux and vapour quality}

Two phase frictional pressure drop as a function of the exit vapour quality at different mass fluxes for $1.70 \mathrm{~mm}$ and $1.224 \mathrm{~mm}$ tubes, at a saturation temperature of $43{ }^{\circ} \mathrm{C}$ is shown in Fig. 5 and Fig. 6 respectively. As expected, the pressure drop increases exponentially with mass flux. It can also be seen that the two phase frictional pressure drop is higher for higher exit vapour quality because the average velocity increases due to increase in specific volume at higher vapour fractions. The influence of vapour quality is observed to be more pronounced at higher mass fluxes. Similar trends were also observed by Ali et al. [16]. Single phase pressure drop values corresponding to each mass flux are also shown in Figs. 5 and 6. It can be seen from Fig. 6 for $1.224 \mathrm{~mm}$ tube that the extrapolation of the two phase pressure drop values of each mass flux to zero vapour fraction more or less corresponds to single phase pressure drop values. Some deviations of two phase pressure drop values with single phase values are observed for the $1.70 \mathrm{~mm}$ tube (as can be seen in Fig. 5). This can be explained by the large uncertainty in low pressure drop readings.

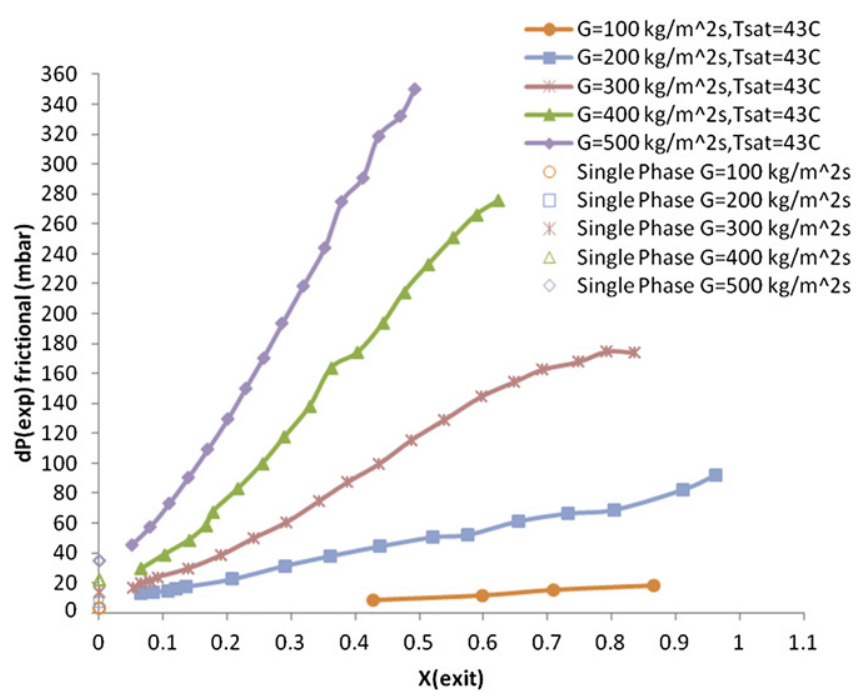

Fig. 6. Two phase frictional pressure drop versus exit vapour quality of $1.224 \mathrm{~mm}$ tube at $T_{\text {sat }}=43^{\circ} \mathrm{C}$.

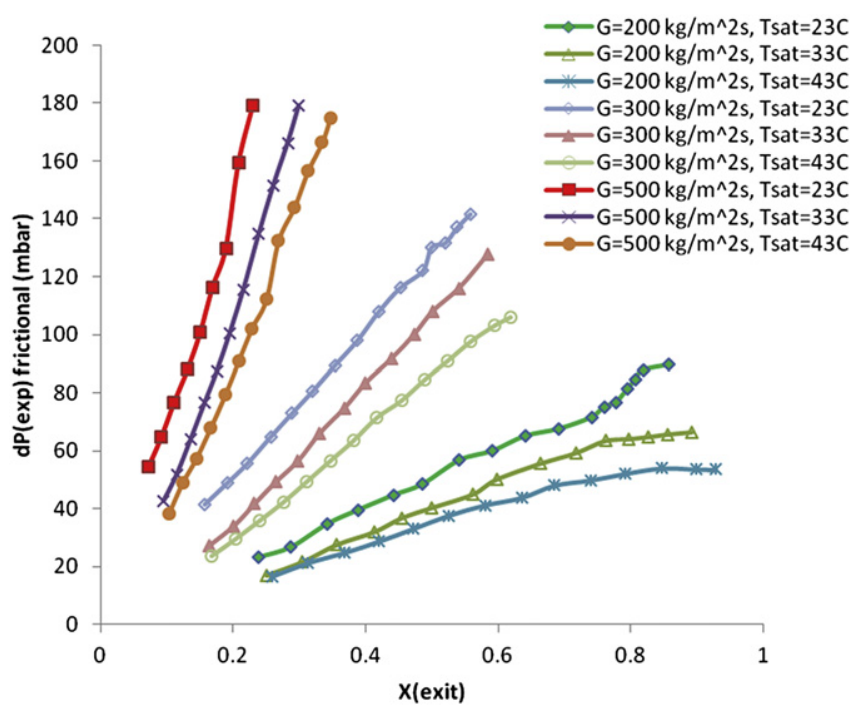

Fig. 7. Two phase frictional pressure drop of $1.70 \mathrm{~mm}$ tube as a function of exit vapour quality and mass flux at different saturation temperatures.

\subsection{Effect of saturation temperature}

Effect of saturation temperature on two phase frictional pressure drop in $1.70 \mathrm{~mm}$ and $1.224 \mathrm{~mm}$ tubes is shown in Fig. 7 and Fig. 8 respectively. The two phase frictional pressure drop is plotted against vapour qualities for three saturation temperatures in Fig. 7 and the two phase pressure drop is plotted versus mass fluxes for three saturation temperatures in Fig. 8. As can be seen, two phase frictional pressure drop is lower for higher saturation temperatures. This can be explained by the fact that the vapour velocity (due to higher vapour density) and also the liquid viscosity decrease with saturation temperature which result in lower pressure drop. These types of trends are also observed by Choi et al. [17] and Revellin and Thome [18]. It can also be observed from Fig. 8 that the influence of saturation temperature is more obvious at high heat flux, i.e. pressure drop at lower saturation temperature increases more at same mass flux with increasing heat flux due to the increased vapour fraction. It can also be seen from Fig. 7 that for

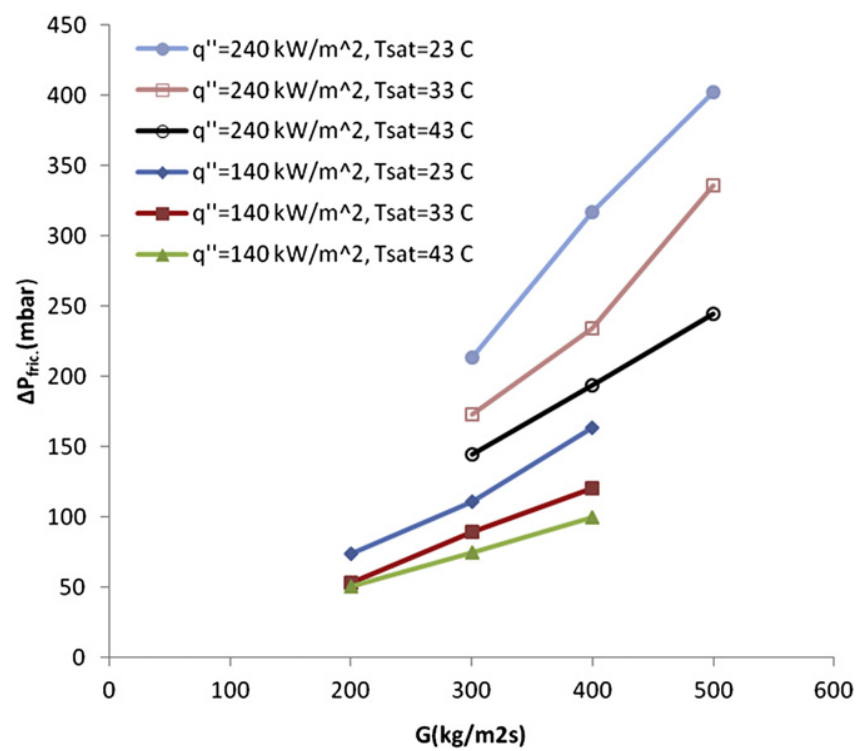

Fig. 8. Two phase frictional pressure drop of $1.224 \mathrm{~mm}$ tube as a function of mass flux and heat flux at different saturation temperatures. 
a given vapour fraction, the difference between the two phase pressure drop at $23{ }^{\circ} \mathrm{C}$ and $33^{\circ} \mathrm{C}$ is higher than the difference between $33^{\circ} \mathrm{C}$ and $43^{\circ} \mathrm{C}$. The difference of liquid to vapour density ratio decreases as we go from lower to higher saturation temperatures which can be a reason for this non uniform difference.

\subsection{Effect of internal diameter}

The two phase frictional pressure drop is plotted in Fig. 9 versus exit vapour fraction for the two tube diameters (fluid was always slightly subcooled at the inlet). As can be seen, pressure drop is higher for the lower diameter tube at equal mass fluxes. The higher pressure drop in the smaller diameter tube is caused by the higher wall shear stress, caused by the higher velocity gradient in this tube. Similar results were also observed by Revellin and Thome [18].

\section{Comparison with correlations}

The two phase pressure drop is compared with well known correlations from the literature. The details of the presented correlations can be found in Table 2 and Table 3. The two phase frictional pressure drop gradients are calculated by dividing the test section in ten segments for each correlation and these local pressure drop gradients are summed up to calculate the total two phase frictional pressure drop.

\subsection{Comparison with macro scale correlations}

Fig. 10a shows the experimental two phase frictional pressure drop plotted versus predicted frictional pressure drop by the homogeneous model using the two phase viscosity definition of Chicchitti et al. [19]. The homogeneous model assumes equal velocities of vapour and liquid and the fluid is considered as single phase. This model under predicts the data with a Mean Absolute Deviation (MAD) of $27 \%$. Similar trends were also reported by Owhaib et al. [3]. It should be noted that the spread in the results is small, and that the deviation is linear, indicating that with a change in the leading constant this correlation would give good predictions for all tests.

The predictions of the Lockhart and Martinelli correlation [20] are shown in Fig. 10b.This correlation is based on the separated

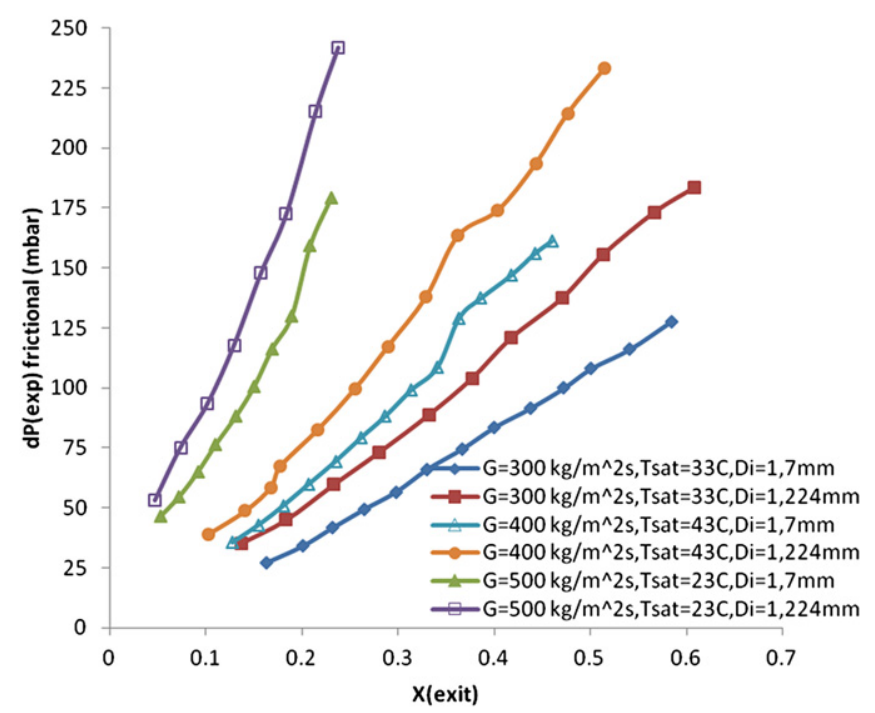

Fig. 9. Two phase frictional pressure drop versus exit vapour quality for different diameters. flow model. This is the only correlation used in this study that predicts the data well at higher mass fluxes and high outlet vapour but overall this correlation over predicts the experimental data with a MAD of $39 \%$, and the spread of the predictions is large.

Many micro scale correlations are modified forms of the Lockhart and Martinelli correlation [20]. This correlation uses a two phase multiplier to determine the two phase frictional pressure gradient. The two phase multiplier is a function of the Martinelli parameter $X$ and the Chisholm parameter $C$. The value of $C$ varies from 5 to 20 depending on the liquid and gas flow regimes [29]. In this study according to the flow regimes in these experiments, mostly the $C$ value of 12 and 20 is used. The two phase multiplier with different values of $C$ and Martinelli parameter for all saturation conditions and diameters are plotted in Fig. 11. The experimental data points are also shown in the Fig. 11. From these plots, it can be observed that if a $C$ value of $4-6$ for $1.70 \mathrm{~mm}$ tube and a value of 9-12 for $1.224 \mathrm{~mm}$ tube are used then the experimental data can be predicted quite precisely by Lockhart and Martinelli Correlation [20]. The $C$ value may be calculated by incorporating the factors which are dominant in micro channels. It has been suggested that if the Lockhart and Martinelli correlation [20] is to be used, parameter $C$ should be determined not only from the flow regimes, but also from the channel size [21].

A comparison of the Chisholm correlation [9] with our experimental data is presented in Fig. 10c.This correlation was developed for turbulent flow pressure drop. This correlation over predicts our experimental data with a MAD of $100 \%$ mainly due to over prediction of the lower pressure drops, for which there are many data points. The spread of the data is slightly less than for the Lockhart-Martinelli correlation [20].

Fig. 10d shows the comparison of experimental two phase frictional pressure drop with the Friedel correlation [22]. As the Lockhart and Martinelli [20] correlation, this correlation is based on the separated flow model. This correlation is developed for macro scale channels where the flow is turbulent even at lower mass fluxes in contrary to micro scale channels, where the flow is laminar except at the highest mass fluxes. This correlation predicts the data with MAD of $25 \%$ and in general, the predictions are similar to that of the homogeneous model.

Fig. 10e shows the comparison of the Müller Steinhagen and Heck [23] correlation with the experimental frictional pressure drop. Tribbe and Müller Steinhagen [24] showed by using air-oil, air-water, steam-water and several refrigerants that this correlation is one of the best predicting methods of two phase pressure gradient in macrochannels. This correlation is able to predict our experimental results for the two tubes with a MAD of $27 \%$ with a small spread of the results, similar to the homogeneous model.

The Grönnerud [11] correlation was developed for refrigerants in larger diameter tubes. This correlation under predicts our experimental data with a MAD of $51 \%$ as is shown in Fig. 10f. Also, the spread of the results is large.

Da Silva Lima et al. [10] observed similar predictions of Lockhart and Martinelli [20], Friedel correlation [22] and Müller Steinhagen and Heck [23] when they performed experiments with ammonia in a smooth horizontal macro channel of $14 \mathrm{~mm}$ internal diameter.

\subsection{Comparison with micro scale correlations}

The micro scale correlations are also compared with the experimental data of ammonia to check their predicting capability.

Predictions of the micro channel correlation suggested by Mishima and Hibiki [7] are shown in Fig. 12a. This correlation is a modified form of the Lockhart and Martinelli [20] correlation in which a new $C$ value is suggested by incorporating the effect of channel diameter. As shown, the spread is very small, but the MAD 

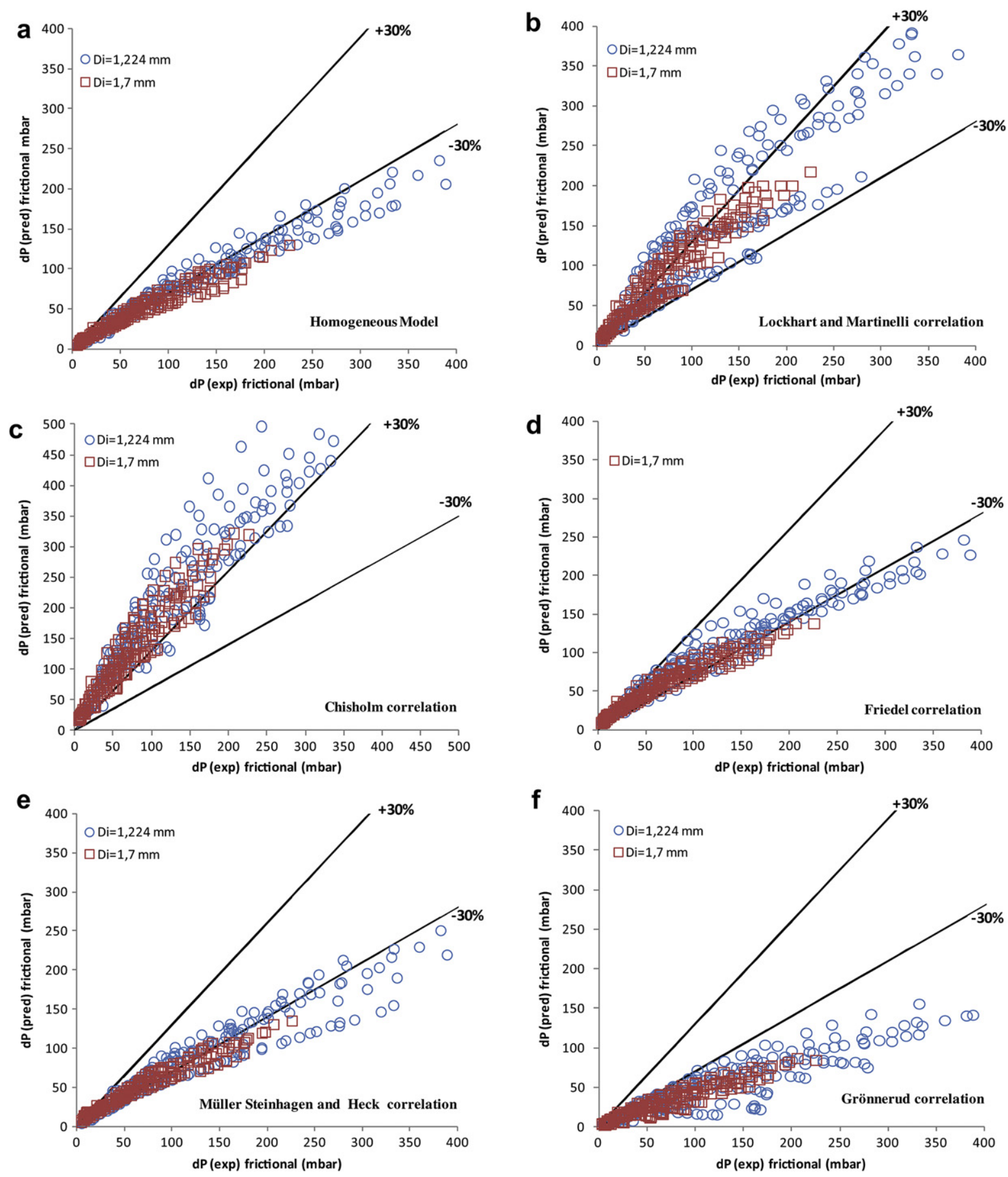

Fig. 10. Comparison of two phase frictional pressure drop with macro scale correlations.

is fairly large, $32 \%$, mainly due to large deviations for the case of high pressure drop, i.e. high mass flux and/or high outlet vapour fraction. Owhaib et al. [3] did flow boiling experiments of R134a in a vertical stain less steel test section in the same test rig as used in this study and Ali et al. [16] performed experiments of R134a in a horizontal glass test section. In these studies it was observed that Mishima and Hibiki [7] predicted the experimental data with a MAD of $22 \%$ and $19 \%$ respectively. Therefore Mishima and Hibiki [7] correlation under predicted the experimental data more in this study, with ammonia, than in our previous studies with R134a $[3,16]$ but with similar prediction trends. Still, the small spread in the results indicates that this correlation is able to catch the influence of important parameters.

The Zhang and Webb [25] correlation is a modified form of the Friedel [22] correlation. They excluded the Weber number and the Froude number because the two phase multiplier in the Friedel [22] correlation was a weak function of $W e$ and $F r$ and included the effect of reduced pressure. This correlation predicts most of the data within $\pm 30 \%$. However, the spread is large, as can be seen in Fig. 12 b. The MAD is $29 \%$.

The correlation of Tran et al. [26] incorporates the surface tension effects and confinement number. This correlation was found to work 

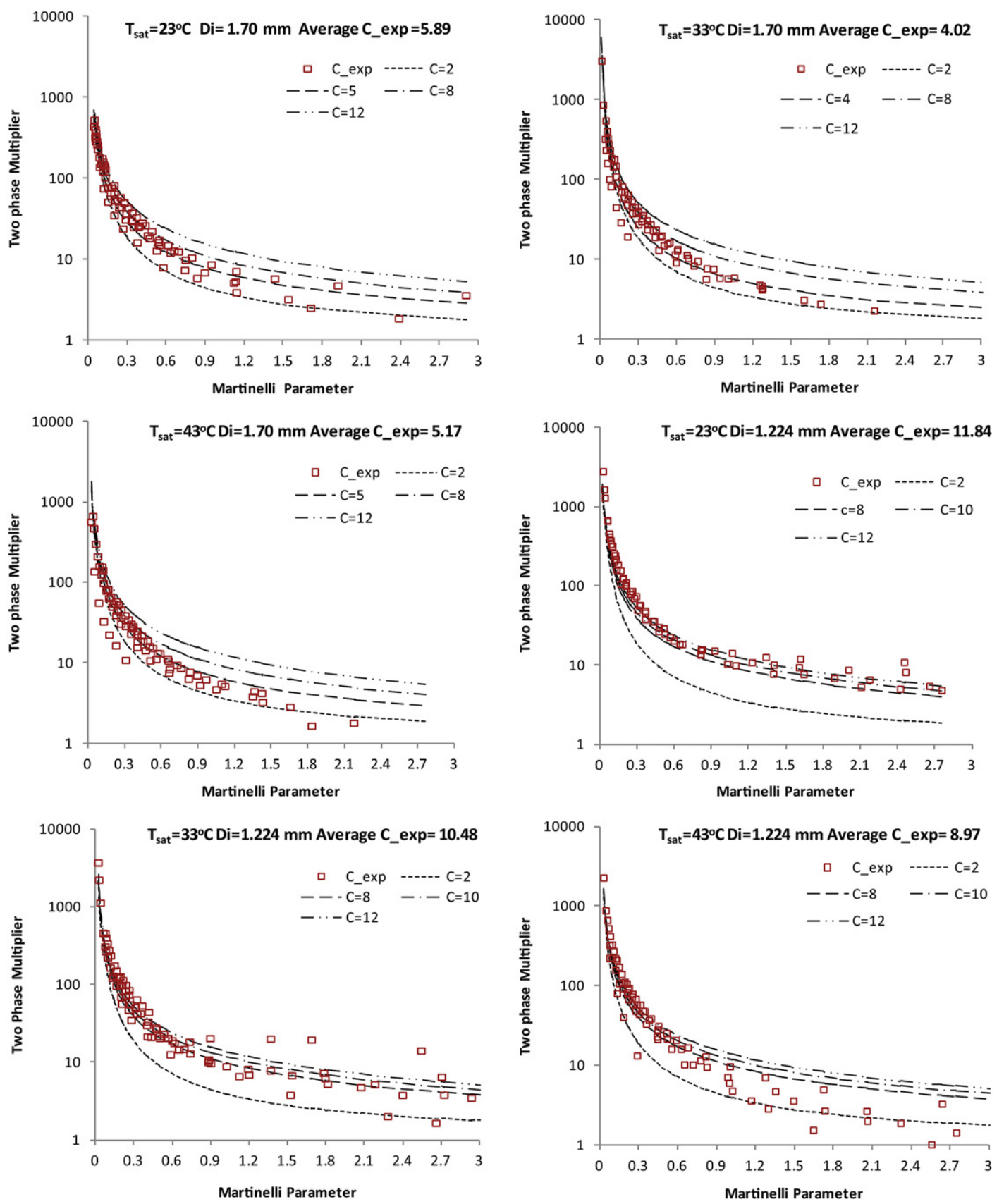

Fig. 11. Two phase multiplier versus Martinelli parameter for the two test sections at all saturation conditions.

well in our previous study for R134a by Ali et al. [16] but for the ammonia data in this study, this correlation over predicts the data with a MAD of $205 \%$. Also, the deviation is much larger for the smaller diameter tube. The data is shown in Fig. 12c. Cavallini et al. [27] observed similar predicting trends when they compared their experimental data of three refrigerants (R236ea, R134a, R410A) in multiport mini channels with Tran et al. [26] correlation.

\section{New proposed correlation}

To develop good prediction method for the two phase pressure drop in mini and micro channels, there are certain parameters like surface tension and confinement effects which need to be considered in addition to the parameters normally considered in macro channels. One way to consider these parameters is to include the Confinement number ( $\mathrm{Co}$ ) defined as;

$C o=\sqrt{\frac{\sigma}{D^{2} \cdot g \cdot\left(\rho_{L}-\rho_{g}\right)}}$

If $C o$ is greater than one, which is the case in this study then the surface tension forces becomes important. Tran et al. [26] developed a micro channel correlation with the inclusion of surface tension in terms of the Confinement number $(\mathrm{Co})$. The Confinement number of different fluids vary under the same experimental conditions. For the same hydraulic diameter, the Confinement number of ammonia is more than two times that of R134a, R22 and R113 on the basis of which Tran et el [26]. correlation was developed Therefore, in this 

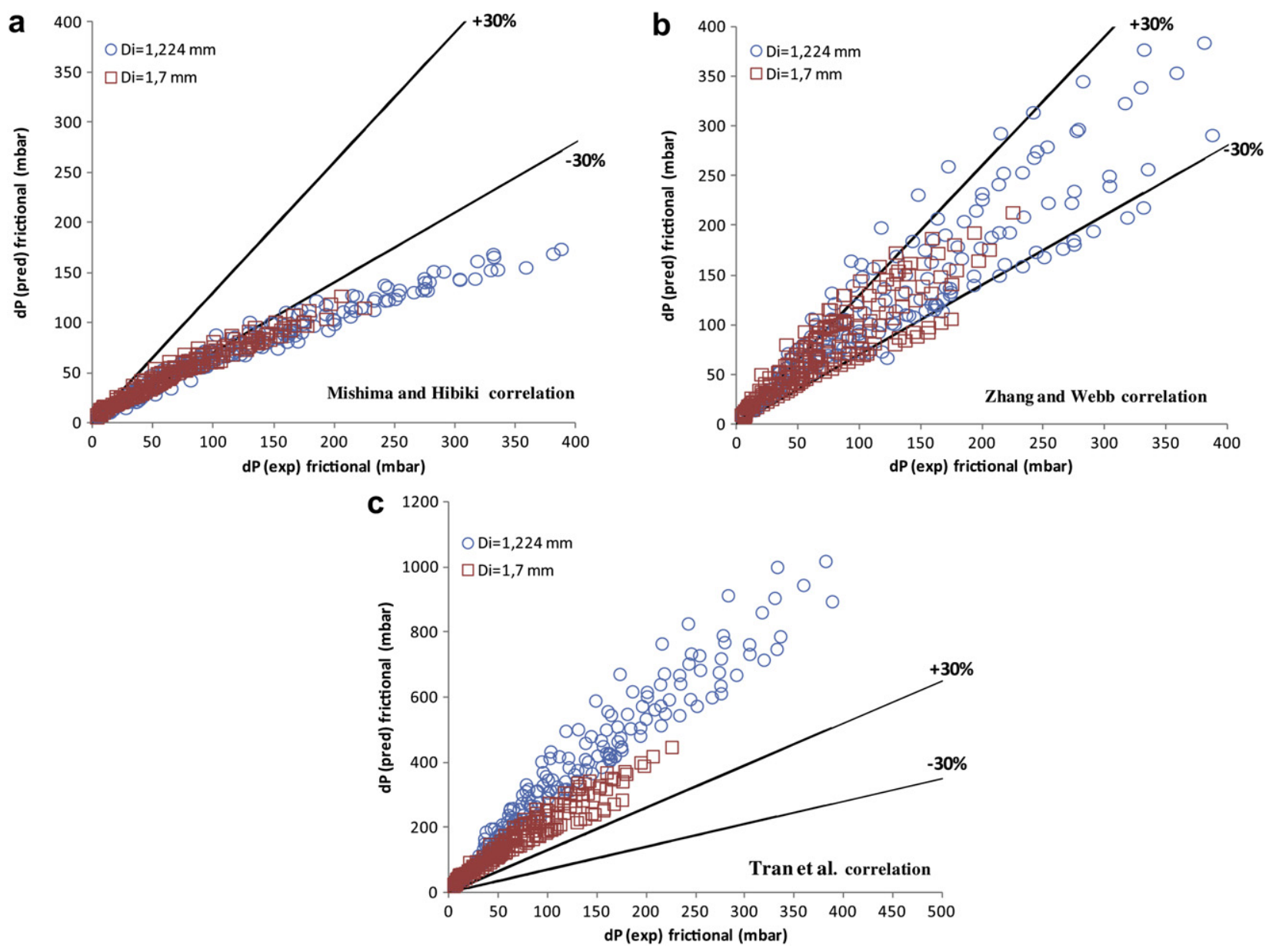

Fig. 12. Comparison of two phase frictional pressure drop with micro scale correlations.

study Tran et al. [26] correlation has been modified for the prediction of ammonia two phase pressure drop. The new proposed correlation, as can be seen in Fig. 13, predicts all the experimental data with MAD of $16 \%$ and $86 \%$ of the experimental data is within the range of $\pm 30 \%$. The functional form of the proposed correlation (modified form of Tran et al. [26] correlation) is;

$\left(\frac{\mathrm{d} p}{\mathrm{~d} z}\right)_{f}=\left(\frac{\mathrm{d} p}{\mathrm{~d} z}\right)_{\mathrm{LO}} \Phi_{\mathrm{LO}}^{2}$

$\Phi_{\mathrm{LO}}^{2}=1+\left(4.3 Y^{2}-1\right) \cdot\left[0.2 \mathrm{Co}^{1.2} \chi^{0.875}(1-\chi)^{0.875}+x^{1.75}\right]$

$Y^{2}=\frac{\left(\frac{\mathrm{d} p}{\mathrm{~d} z}\right)_{\mathrm{VO}}}{\left(\frac{\mathrm{d} p}{\mathrm{~d} z}\right)_{\text {LO }}}$

\section{Conclusions}

Two phase pressure drop experiments of ammonia were performed in two stainless steel (AISI 316) vertical channels of internal diameters of $1.70 \mathrm{~mm}$ and $1.224 \mathrm{~mm}$. The tests were done at three different saturation pressures. Effects of different parameters on two phase pressure drop were investigated. The main conclusions are;
$>$ The comparison of the experimental data of ammonia with the existing macro scale correlations shows that none of the correlations predicted the data well. The predicting methods which give better predictions include homogeneous model, Müller Steinhagen and Heck [23] and Friedel [22], all three under predicting the experimental results with a rather small spread among the data points. The mean absolute deviations,

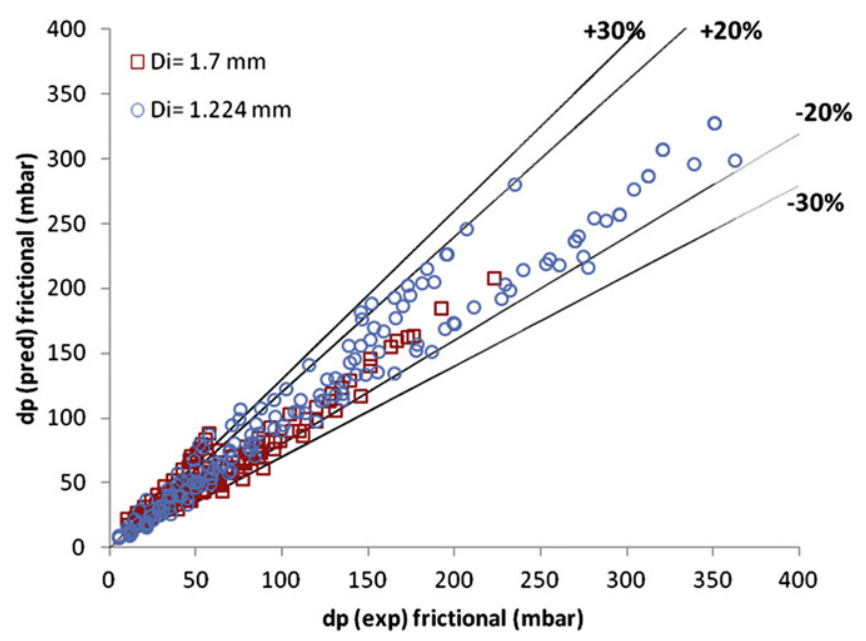

Fig. 13. Comparison of two phase experimental frictional pressure drop with proposed correlation. 
MAD, were $27 \%, 27 \%$ and $25 \%$ for these correlations respectively.

$>$ Micro scale correlations like Zhang and Webb [25] and Mishima and Hibiki [7] predicted our experimental data with a MAD of $29 \%$ and $32 \%$ respectively. The spread between the data points was much smaller for the Mishima and Hibiki correlation, but this correlation under predicted most data. The Zhang and Webb correlation caught the general trend, but the spread in the data was much larger.

$>$ A new proposed correlation, a modified form of Tran et al. [26] correlation, is able to predict all experimental data with MAD of $16 \%$ and $86 \%$ of the experimental data is within $\pm 30 \%$ range.

\section{Acknowledgement}

The authors gratefully acknowledge the scholarship awarded by Higher Education Commission Pakistan [HEC] to conduct this research as part of PhD studies at Department of Energy Technology, Royal Institute of Technology, KTH, Sweden.

\section{Nomenclature}

$\begin{array}{ll}A & \text { heat transfer area, } \mathrm{m}^{2} \\ C_{p} & \text { specific heat, } \mathrm{J} / \mathrm{kg} \mathrm{K} \\ D & \text { diameter, } \mathrm{m} \\ \mathrm{DC} & \text { direct current } \\ f & \text { friction factor, }- \\ G & \text { mass flux, } \mathrm{kg} / \mathrm{m}^{2} \mathrm{~s} \\ g & \text { acceleration of gravity, } \mathrm{m} / \mathrm{s}^{2} \\ I & \text { current, } \mathrm{A} \\ i_{\mathrm{lv}} & \text { latent heat of vapourization, } \mathrm{J} / \mathrm{kg} \\ k & \text { thermal conductivity, } \mathrm{W} / \mathrm{m} \mathrm{K} \\ L & \text { length, } \mathrm{m} \\ \mathrm{MAD} & \text { mean absolute deviation, }=[1 / N]\left[\Sigma\left|X_{\mathrm{pred}}-X_{\text {exp }}\right| / X_{\text {exp }}\right](\%) \\ m & \text { mass flow of refrigerant, } \mathrm{kg} / \mathrm{s} \\ P & \text { pressure, bar } \\ P_{c} & \text { critical pressure, bar } \\ P_{r} & \text { reduced pressure, }- \\ q^{\prime \prime} & \text { heat flux, } \mathrm{W} / \mathrm{m}^{2} \\ T & \text { temperature, }{ }^{\circ} \mathrm{C} \\ u & \text { velocity, m/s } \\ \mathrm{US} & \text { superficial velocity, } \mathrm{m} / \mathrm{s} \\ V & \text { voltage, } \mathrm{V} \\ x & \text { vapour fraction, }- \\ z & \text { axial position, } \mathrm{m} \\ \mathrm{z}_{\mathrm{O}} & \text { position where boiling starts, } \mathrm{m}\end{array}$

\section{Greek letters}

$\Phi \quad$ two-phase flow multiplier

$\mu \quad$ dynamic viscosity, Pa s

$\rho \quad$ density, $\mathrm{kg} / \mathrm{m}^{3}$

$\Delta P \quad$ pressure difference, mbar

$\sigma \quad$ surface tension, $\mathrm{N} / \mathrm{m}$

$\alpha \quad$ void fraction

\begin{tabular}{ll}
\multicolumn{2}{l}{ Subscripts } \\
acc & acceleration \\
atm & atmospheric \\
$c$ & cross-sectional \\
crit & critical \\
exp & experimental \\
fric & frictional \\
$g$ & gas
\end{tabular}

$\begin{array}{ll}\text { grav } & \text { gravitational } \\ h & \text { heated } \\ i & \text { inside } \\ \text { ic } & \text { inlet contraction } \\ \text { in } & \text { inlet } \\ L & \text { liquid } \\ \text { lam } & \text { laminar } \\ \text { lo } & \text { liquid only } \\ o & \text { outside } \\ \text { oe } & \text { outlet expansion } \\ \text { pred } & \text { predicted } \\ \text { sat } & \text { saturation } \\ \text { sp } & \text { single phase } \\ \text { tp } & \text { two phase } \\ \text { turb } & \text { turbulent } \\ v & \text { vapour } \\ \text { vo } & \text { vapour only }\end{array}$

Non-dimensional groups

Co $\quad$ confinement number, $=\sqrt{\frac{\sigma}{D^{2} \cdot g \cdot\left(\rho_{L}-\rho_{g}\right)}}$

Fr Froude number, $=\frac{G^{2}}{\rho^{2} g D_{i}}$

Re Reynolds number, $=\frac{\mathrm{GD}}{\mu}$

We Weber number, $=\frac{G^{2} D_{i}}{\rho \sigma}$

$X^{2} \quad$ Lockhart-Martinelli parameter $=\left[\frac{\left(\frac{\mathrm{d} p}{\mathrm{~d} z}\right)_{L}}{\left(\frac{\mathrm{d} p}{\mathrm{~d} z}\right)_{V}}\right]$

\section{References}

[1] S.S. Bertsch, E.A. Groll, S.V. Garimella, Refrigerant flow boiling heat transfer in parallel micro channels as a function of local vapour quality, International Journal of Heat and Mass Transfer 51 (2008) 4775-4787.

[2] Y.W. Hwang, M.S. Kim, Pressure drop in micro tubes and correlation development, International Journal of Heat and Mass Transfer 49 (2006) 1804-1812.

[3] W. Owhaib, Experimental Heat Transfer, Pressure Drop, and Flow Visualization Of R-134a in vertical Mini/Micro tubes, Doctoral Thesis in Energy Technology, KTH, Stockholm Sweden (2007) ISBN 978-91-7178-594-7.

[4] E.K. Ungar, J.D. Cornwell, Two phase pressure drop of ammonia in small diameter horizontal tubes, AIAA Paper 92 (1992) 3891.

[5] W.H. McAdams, W.K. Woods, R.L. Bryan, Vaporization inside horizontal tubesII-benzene-oil mixtures, ASME Transactions 64 (1942) 193.

[6] S. Brandon, P. Hrnjak, Adiabatic two-phase pressure drop of refrigerants in small channels, Journal of Heat Transfer Engineering 28 (8) (2007) 704-712.

[7] K. Mishima, T. Hibiki, Some characteristics of air-water flow in small diameter vertical tubes, International Journal of Multiphase Flow 22 (1996) 703-712.

[8] S. Kabelac, HJ. De Buhr, Flow boiling of ammonia in a plain and a low finned horizontal tube, International Journal of Refrigeration 24 (2001) 41-50.

[9] D. Chisholm, Pressure gradients due to friction during the flow of evaporating two-phase mixtures in smooth tubes and channels, International Journal of Heat and Mass Transfer 16 (1973) 347-348.

[10] R.J. Da Silva Lima, J.M. Quiben, C. Kuhn, T. Boyman, R.J. Thome, Ammonia twophase flow in a horizontal smooth tube: flow pattern observations, diabatic and adiabatic frictional pressure drops and assessment of prediction methods, International Journal of Heat and Mass Transfer 52 (2009) 2273-2288.

[11] R. Grönnerud, Investigation of liquid hold-up, flow-resistance and heat transfer in circulation type evaporators, part IV: two-phase flow resistance in boiling refrigerants, annexe 1972-I, Bull. De I'Inst. du froid (1979).

[12] J. Moreno Quibén, J.R. Thome, Flow pattern based two-phase frictional pressure drop model for horizontal tubes. Part2: new phenomenological model, International Journal of Heat and Fluid Flow 28 (2007) 1060-1072.

[13] H. Blasius, Das Ähnlichkeitsgesetz bei Reibungsvorgäangen in Flüssigkeiten, Forchg. Arb. Ing.- Wes. 131 (1913) (Berlin).

[14] J.G. Collier, J.R. Thome, Convective Boiling and Condensation, third ed. Oxford University Press, 1994.

[15] M.A. Woldesemayat, A.J. Ghajar, Comparison of void fraction correlations for different flow patterns in horizontal and upward inclined pipes, International Journal of Multiphase Flow 33 (2007) 347-370.

[16] R. Ali, B. Palm, M.H. Maqbool, Experimental investigation of two phase pressure drop in a mini channel, Proceedings of the 2nd Micro and Nano Flows Conference West London, UK (September 2009) 1-2. 
[17] K.I. Choi, A.S. Pemitran, J.T. Oh, K. Saito, Pressure drop and heat transfer during two phase flow vaporization of propane in horizontal smooth channels, International Journal of Refrigeration 32 (2009) 837-845.

[18] R. Revellin, J.R. Thome, Adiabatic two phase frictional pressure drops in micro channels, Experimental Thermal and Fluid Sciences 31 (2007) 673-685.

[19] C. Chicchitti, M. Lombardi, G. Silvestri, R. Soldaini, Zavattarelli, Two-phase cooling experiments pressure drop, heat transfer and burnout measurements, Nuclear Energy 7 (6) (1960) 407-425.

[20] R.C. Lockhart, R.W. Martinelli, Proposed correlation of data for isothermal two-phase, two component flow in pipes, Chemical Engineering Progress 45 (1949) 39-48.

[21] H.J. Lee, S.Y. Lee, Pressure drop correlations for two-phase flow within horizontal rectangular channels with small heights, International Journal of Multiphase Flow 27 (2001) 783-796.

[22] L. Friedel, Improved Friction Pressure Drop Correlations for Horizontal and Vertical Two- Phase Pipe Flow, European Two-Phase Flow Group Meeting, Ispra, Italy, 1979, paper E2.

[23] H. Müller-Steinhagen, K. Heck, A simple friction pressure drop correlation for two- phase flow pipes, Chemical Engineering Process 20 (1986) 297-308.
[24] C. Tribbe, H.M. Müller Steinhagen, An evaluation of the performance of phenomenological models for predicting pressure gradient during gas liquid flow in horizontal pipelines, International Journal of Multiphase Flow 26 (2000) 1019-1036.

[25] M. Zhang, R.L. Webb, Correlation of two-phase friction for refrigerants in small-diameter tubes, Experimental Thermal and Fluid Science 25 (2001) 131-139.

[26] T.N. Tran, M.C. Chyu, M.W. Wambsganss, D.M. France, Two phase pressure drop of refrigerants during flow boiling in small channels: an experimental investigation and correlation development, International Journal of Multiphase Flow 26 (2000) 1739-1754.

[27] A. Cavallini, D.D. Col, L. Doretti, M. Matkovic, L. Rossetto, C. Zilio, Twophase frictional pressure gradient of R236ea, R134a and R410A inside multi-port mini-channels, Experimental Thermal and Fluid Science 29 (2005) 861-870.

[28] A.E. Dukler, M. Wicks, R.G. Cleveland, Pressure drop and hold-up in two-phase flow part $\mathrm{A}-\mathrm{a}$ comparison of existing correlations and part $\mathrm{B}-$ an approach through similarity analysis, AIChE Journal. 10 (1) (1964) 38-51.

[29] D. Chisholm, A.D.K. Laird, Two-phase flow in rough tubes, Transactions of ASME 80 (2) (1958) 276-283. 